CESIS Electronic Working Paper Series

Paper No. 330

\title{
Creativity as an integral element of social capital and its role for economic performance
}

\author{
Hans Westlund \\ Martin Andersson \\ Charlie Karlsson
}

November, 2013 


\title{
Creativity as an integral element of social capital and its role for economic performance
}

\author{
By Hans Westlund ${ }^{1}$, Martin Andersson ${ }^{2}$ and Charlie Karlsson ${ }^{3}$
}

\begin{abstract}
In this paper, we focus on the connections between creativity, social capital and economic performance and growth. Our working hypothesis is that both creativity and social capital influences the economy, both each per se, but also through their influence on each other. We regard creativity as one of the sources of entrepreneurship and innovation (although creativity also can have 'bad' consequences if bad actors such as criminals perform it). Depending on the types of networks and the norms and values being distributed in them, social capital can promote entrepreneurship and innovation and thus economic growth, but social capital can have an inhibiting effect on entrepreneurship and innovation. Social capital can contribute to creativity by dynamic networks and/or values and attitudes that promote experimentation, but social capital can also counteract creativity by rigid networks and values that support status quo. Efforts to defend status quo might be creative in a sense, but the creativity that we focus on in this paper, that with positive impact on economic growth, is only found in the social capitals that support economic growth and change.
\end{abstract}

Keywords: Creativity, social capital, norms, values, attitudes, institutions, networks, innovation, entrepreneurship, economic performance, economic growth

JEL Codes: D80, L26, L14, O31, O43, R11

\footnotetext{
${ }^{1}$ Royal Institute of Technology Stockholm \& Jönköping International Business School, hanswes@infra.kth.se

${ }^{2}$ CIRCLE, Lund University \& Blekinge Institute of Technology, Karlskrona, martin.andersson@circle.lu.se,

${ }^{3}$ CESIS, Jönköping International Business School \& Blekinge Institute of Technology, Karlskrona, charlie.karlsson@jibs.hj.se
} 


\section{Introduction}

Creativity and social capital - do these two concepts have anything in common? Do they influence or counteract each other? In addition, how are they related to economic growth? These are some of the questions being dealt with in this paper.

As discussed in Section 2 of this paper, social capital is normally defined in terms of social networks, and norms and values being distributed in these networks. Regarding creativity there are innumerable definitions. Here are two of them that can be found at a website on the topic: ${ }^{1}$ Creativity is any act, idea, or product that changes an existing domain or that transforms an existing domain into a new one... What counts is whether the novelty he or she produces is accepted for inclusion in the domain (Csikszentmihalyi 1996). Creativity is nothing more than seeing and acting on new relationships, thereby bringing them to life (Anderson 1992, p 41).

It is noteworthy that both the above definitions of creativity express a relation to features of social capital. The first definition states that the novelty that creativity represents must be $a c$ cepted, i.e. if the act, idea or product does not bring any change in predominant values of a 'domain' or have the ability to change the domain to a new one it is not a creative novelty. In the centre of the second definition is the concept of new relationships, i.e. new links or networks between various factors that previously have not been connected. These new links or networks does not necessarily have to be social ones, but can be economic, technical, biological, etc. However, social actors, i.e. humans, bring the creative feature of such non-social links and networks there. ${ }^{2}$

Interpreted in this way, creativity seems to be something that changes existing social values or (social and non-social) networks or both, or that creates new social values and (social and non-social) networks. In other words, creativity brings change of the existing norms, values and networks of society's existing social capitals. However, it is not only social capital that creativity is influencing and changing. Creativity changes culture, knowledge, communication, leisure - and production and consumption. Thus, creativity exerts a strong influence on all parts of society.

In this paper, we focus on the connections between creativity, social capital and economic performance and growth. Our working hypothesis is that both creativity and social capital influences the economy, both each per se, but also through their influence on each other. We regard creativity as one of the sources of entrepreneurship and innovation (although creativity also can have 'bad' consequences if bad actors such as criminals perform it). Depending on the types of networks and the norms and values being distributed in them, social capital can promote entrepreneurship and innovation and thus economic growth, but social capital can have an inhibiting effect on entrepreneurship and innovation. Social capital can contribute to creativity by dynamic networks and/or values and attitudes that promote experimentation, but social capital can also counteract creativity by rigid networks and values that support status quo. Efforts to defend status quo might be creative in a sense, but the creativity that we focus on in this paper, that with positive impact on economic growth, is only found in the social capitals that support economic growth and change. 
In Section 2, we start by analysing social capital and its forms, functions and role in economic development. Section 3 discusses creativity, its driving forces and expressions, in particular entrepreneurship and innovation. Section 4 treats social capital as an explanatory factor for creativity, while Section 5 discusses creativity as an element of social capital. The paper ends up in some conclusions in Section 6.

\section{Social capital - forms, functions and role in economic development}

\subsection{The forms and functions of social capital}

As shown by among others Portes and Landolt (1996) the concept and features of social capital has a pre-history dating back to Durkheim and other classical sociologists of the late $19^{\text {th }}$ century. For the modern "founders" of the concept, Bourdieu (1980) and Coleman (1988, 1990), social capital was not a main topic of theirs, but merely an offshoot to their general sociological theories. It was not until Putnam (1993, 1995) published his book "Making Democracy Work" and his article "Bowling Alone: America's Declining Social Capital" that social capital became a worldwide concept, not only among social scientists of various disciplines but also in the public debate, among politicians and other decision-makers, etc.

In the dominating tradition of Putnam, social capital has most often been defined as social networks, norms, and values being distributed in these networks. A main concept in large parts of the social capital literature is that of trust. It can be discussed whether trust is a characteristic of social capital in itself or if it should be included in the category norms and values. Our standpoint is that trust should be included in the latter category.

The network and the norm/value aspects of social capital have also been expressed in the form of social capital's structural, relational and cognitive dimensions (Nahapiet \& Ghoshal 1998). The structural dimension refers to the properties of relations of the networks as a whole, while the relational dimension represents types of personal relationships actors have developed with each other over time, as e.g. respect and friendship that affects their behaviour. This can be interpreted as that the structural dimension is a reflection of the network aspect of social capital at macro level, while the relational dimension reflects the micro level, the individual links of the networks. The according to this view, third dimension of social capital, the cognitive one, consists of "those resources providing shared representations, interpretations, and systems of meaning among parties" (Nahapiet \& Ghoshal 1998, p. 244). Nahapiet \& Ghoshal claimed that this dimension had been overlooked in the literature, but in principle, this dimension is nothing but the norms and values that Putnam mentioned already 1993.

A key question is where social capital can be found in society. Putnam (1993, 1995, and 2000) never discussed this issue but seems to have taken for granted that social capital is a feature of the civic (or civil) society. ${ }^{3}$ His measures of social capital have centred on associational activity and other civic activities, and trust in other people. The mainstream of the social capital literature has stuck to this Putnamian tradition and focused on networks, norms and values, in particular trust, of the civil society. However, the question that then arises is "...how these phenomena outside the civil society should be denominated. Should the term 
social capital only be applied to the civil society or should it be interpreted literally and include social networks, relations, values, norms etc. also within business life and the public sector? Or to ask the question in a very simple way: is social capital something that is created and used only during people's leisure time?” (Westlund 2006, p. 4).

A growing literature in the economic disciplines is taking this broader perspective on social capital's occurrence in the sectors of society, and is studying the social capital of firms and other organizations. ${ }^{4}$ This is also in line with the arguments raised by Westlund and Adam (2010) saying that, compared with the social capital of business life (and government), the social capital of the civil society seldom can be the type of social capital that has the strongest impact on economic growth of firms, regions and countries.

A third division of social capital's characteristics concerns the functions of the links of the social networks, and the norms and values that contribute to the creation or termination, supporting or prevention these links. Westlund and Nilsson (2005) discussed these functions in terms of internal and external links respectively. Another, more used division is that in bonding and bridging links, and the norms and values connected to them (Putnam 2000). ${ }^{5}$ Bonding links have the function to "bond" the actors of the (spatial or organizational) unit in question together, i.e. to secure the solidarity and cohesion of the unit. Bridging links are links between actors of the unit and actors of other units. The function of bridging links is to connect the group and its actors with "the rest of society", among other things to get access to external information, knowledge and other resources. To these two functions of social capital Woolcock (2000) has added a third, viz. linking social capital. Woolcock defines linking social capital as the vertical relationships between actors with different possession of power. Linking social capital empowers individuals and groups to access resources, ideas and information from policymakers and other decision-makers. However, the social links between a centre of power and its "clients" should probably also be denominated as a linking social capital.

We have already indicated that social capital exists at a number of various spatial and organizational levels. This is illustrated in Figure 1. At the lowest level is the individual actor, who is connected to other individuals within a group/organization by group-internal, bonding, horizontal links. Simultaneously, the group/organization, which the individual belongs to, is a decision-maker of higher order, which means that the links between the individual and the group are of a vertical (linking) character.

The second lowest level is the local group/organization. Groups within the same locality can hardly exist very independent of each other, but are coupled to each other by horizontal links. Collectively these co-located groups form a place with a local, place-bound social capital with a higher degree of heterogeneity than that of each group. In contrast to an organization, a place is not a decision-maker, but the social networks of a place form opportunities and restrictions that influence the decision-making of individuals and organizations. The local groups/organizations and the places they are located in also have vertical links to actors at higher, regional, national and international levels. Social capital at regional level is more het- 
erogeneous than at local level, etc., and the social capitals at these higher spatial levels constitute opportunities and restrictions, affecting decision-making as well.

The differences in homogeneity between social capitals at different levels constitute the fundamental problem in aggregating social capital. Knowledge about links on one level does not necessarily give any information about links on a higher level. Information about links between two levels may not be valid at all for links between other levels. Glaeser et al. (2002, p. 442) recognize this when they point out that "the complexity of aggregation means that the determinants of social capital at the individual level may not always determine social capital at the society-level."

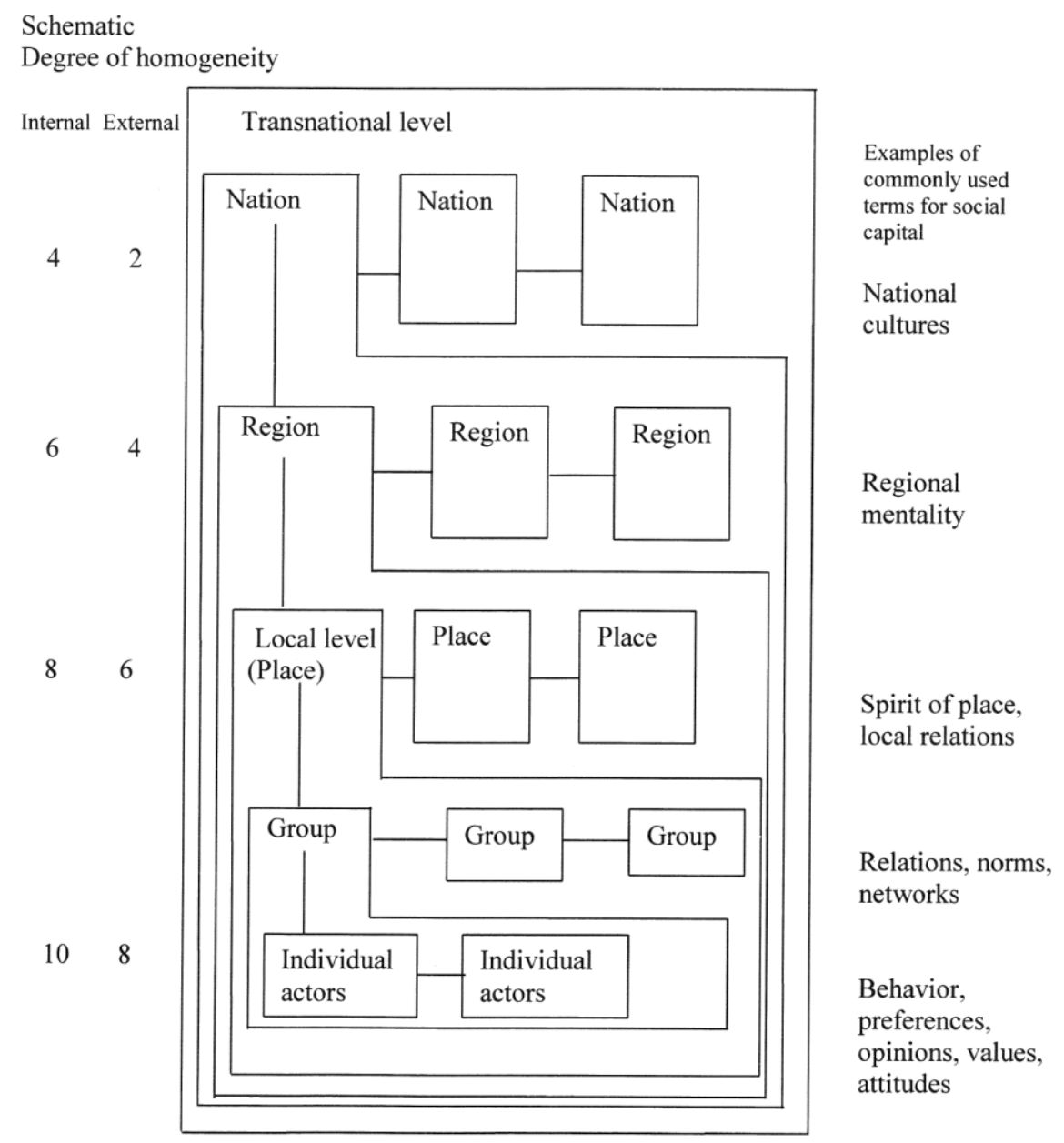

Figure 1. Spatial levels, degree of homogeneity, horizontal and vertical links between actors and levels, and examples of commonly used terms for social capital at different levels. (Source: Westlund and Bolton 2003).

The conclusion from Figure 1 is that analyses of the interplay between social capital and e.g. creativity must be adapted to the spatial or organizational level in focus. However, attempts to aggregate features of social capital specific to different levels into a "general" level run up against great problems of principle. The common denominator of social capital must be sought at each level individually. 


\subsection{The role of social capital in economic development}

As seen above, social capital has been divided after a number of different forms and functions. This subsection deals with the issue of whether these forms and functions vary with respect to their influence on economic growth and development.

\section{The role of structural, relational and cognitive social capital}

According to economic theory, structural social capital, i.e. social networks, should mainly have a positive influence on economic growth and development. The reason is the existence of market imperfections, e.g. that information is not immediately spread among the economic actors, the fact that there exist transaction costs, etc. In principle, it can be argued that similar arguments that Coase (1937) presented for the existence of organizations like firms in a market economy, and those Buchanan (1965) brought for the existence of clubs, can be raised for the existence of social networks and their (positive) effects on economic development. They lower the costs of transfer of information and other transaction costs. However, social networks are more complicated types of organizations than firms are in terms of their objectives and aims. Firms' objectives mainly are economic (under legal and social restrictions), whereas the objectives of social networks can be much more diverse. Many social networks have probably not any economic objectives, but as argued by Putnam (1993), voluntary associations and other social networks can still play a positive role for economic development, since they increase humans' interactions and contribute to creating and strengthening trust among the participants of the networks. However, on the other hand there are many examples of social networks that do not play a positive economic role from society's point of view. Mafia and other criminal gangs and networks are obvious examples of this. However, in this group we can also count spatially and relational bounded networks of 'too much' reciprocity, in which there are expectations that the entrepreneur's successful economic results should be shared with a whole group, which leaves an initially successful entrepreneur without sufficient resources to expand (Portes \& Landold 1996).

The discussion above implies that positive influences of structural social capital on economic development cannot always be taken for granted. It is the cognitive social capital - the values and norms being distributed in the networks of the structural social capital - that decides whether the social networks are having a positive impact on economic growth or not. This was recognized already by Schumpeter (although in other terms) when he pointed out "the reaction of the social environment against one who wishes to do something new.... any deviating conduct by a member of a social group is condemned.... This opposition is stronger in primitive stages of culture than in others, but it is never absent... The manifestation of condemnation may even come to social ostracism and finally to physical prevention or to direct attack...." (Schumpeter 1934:86-87). While Schumpeter underscored the possible negative impact of the (in our terms) cognitive social capital on entrepreneurship and economic change, the social capital literature has mainly focused on the positive impacts. The by far most acclaimed positive factor of cognitive social capital is that of trust. The main argument is that if people trust each other, this will lead to a number of positive effects. The availability of credits for investments should increase and interest rates would tend to be lower; the spread of information and the speed of the spread would be higher, thereby improving markets' 
functions; knowledge spillovers would increase contributing to creativity and innovativeness in the form of 'new combinations of production factors' i.e. innovations. Already Putnam (1993) recognized trust as a key element of social capital. The availability of easily accessible statistics at national (and in certain countries at regional) level through the World Value Surveys and similar, have made trust the single most used empirical measure of social capital.

The dominance of trust as measure of social capital has meant that other components of cognitive social capital that affect economic performance have been somewhat overshadowed in empirical research. Factors like tolerance, attitudes to change, and diversity have been highlighted by Florida (2002) but have so far not made much impact in the social capital literature. $^{6}$

The third form of social capital in this division, the relational social capital consists in contrast to the macro-level structural social capital, of individual relationships and links between actors at the micro level. The economic impact of these links depends primarily of which actors, or more formally expressed, which nodes that are linked together. For economic performance, it should be obvious that links between economic actors are of more importance than links between non-economic actors. From the perspective of innovation systems and triplehelix theory, it could be objected that connections across the business, research and public sectors are also of great importance. However, such sectorial views are much more relevant for the structural, macro-type of social capital than for the individual, relational social capital type.

\section{Business-related, governmental and civil social capital $^{7}$}

The discussion of different societal sectors and their economic impact can of course not be isolated from the sectors' various social capitals. According to the theories of innovation systems and triple-helix, three types of organizations - firms, universities and government should cooperate in order to meet the needs of the knowledge economy. Universities should provide the knowledge, government should provide favourable institutions and development resources and firms provide resources and know-how for commercialization. However, a dilemma is that the three actor blocs are based on different principles of exchange, which are reflected in different rules of the game. Based on Polanyi (1944) it can be argued that a firm bases its activities on a market principle where profit is a necessary ingredient. For public government, which has the power to collect the resources of individuals and organizations and redistribute them, the basic principle is redistribution. The third type of organization, the academy (or university), is for its part historically predominated by a third principle, viz. reciprocity - a mutual exchange of knowledge and ideas. Academy-produced knowledge is by tradition neither sold on a market nor taken from one actor and given to another, but exchanged and valued by equals (peers) without any losses.

It is understood that organizations with such principal differences build social capital with very dissimilar networks. These networks connect different types of actors and are based on different norms and attitudes. The activities of the firm are executed with the aim of making profit. The firm builds technical and economic links internally and to external actors. These links are established and maintained if they are assessed to bring net revenues. The social 
networks of a firm are based on more compound motives. Creation and maintenance of social links that the firm makes deliberate investment in - e.g. corporate culture, personal customer relations, etc. - are in principle controlled by the same net revenue principle as economic links. However, many social networks are unintended by-products of other interactions (Putnam 1993). Thus, many social links of the firm are by-products of its economic networks. To the extent to which human beings are involved, social links/relations develop because of the economic links. A firm makes certain deliberate investment in social networks, but many of the social networks of a firm are by-products of technical and economic networks.

Accordingly, companies' social networks have two sources: Deliberate, formal investment decisions by management on different levels, in accordance with the firm's basic mission, and spontaneous, informal investment decisions by individuals, originally connected through the economic links, based on volition to interact, to socialize. The volition to interact is connected to the "affinity" between the actors (cf. Johansson and Westin 1994). For a social link to be established, the nodes/actors should have something in common (e.g. some norms, values or preferences, or some minimum degree of mutual trust).

The second type of organization, public government, is run by political objectives, but a fundamental need for public government is to legitimize itself. For this reason, it builds social links to the citizens and organizations of society, beside the necessary economic and technical networks it needs to fulfil its objectives. The activities of public governments, as in the case of the firms, also create "uncontrolled" social networks as by-products. However, as the basic mission of public government is to redistribute the resources of society, both the intended and unintended social networks of government, and the norms and values distributed in them, fulfil other objectives than the social networks of the firm.

The third type of organization is the academy. In spite of the fact that it is financed in a number of different ways, it has an international, joint identity with missions, objectives and norms. This academy-internal social capital is an important reason behind the academy's relative independence vis-à-vis other actors in society. It is on the other hand a potential obstacle to collaboration with organizations having other missions and social capitals.

These three types of organizations build social capitals deliberately and contribute to unintended, spontaneous social capital building as well. Figure 2 describes the different component parts of organizations' social capital. Depending on the organization's mission, certain norms, values and attitudes are developed, which in their turn govern the extension and allocation of the organization's internal and external links.

It can be argued that organizations' social capitals have become more and more complex. The assembly line - the archetypical symbol for manufacturing industrialism - required few social skills of its workers, not even a common language. In contrast, work in a consultancy company of today requires ability to cooperate, build networks and even certain attitudes. People without this social competence do not get access to the social capital of these companies of the knowledge economy. 


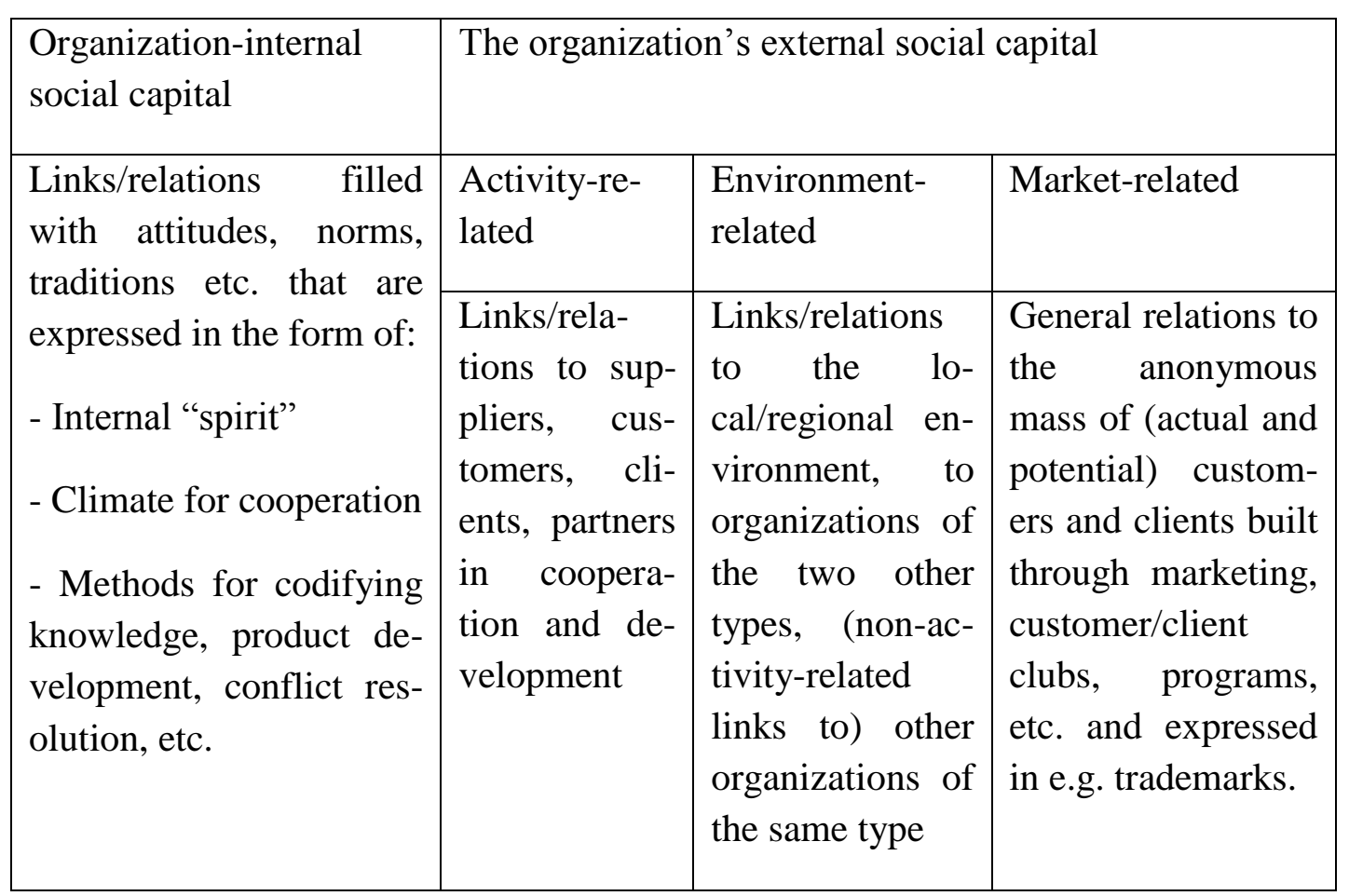

Figure 2. Social capital of organizations broken down into different component parts.

In the period when public government was small, it was held together by a strong social capital, expressed in the ideology of the public official, standing above the interest groups of society. The increased involvement of government in different areas of society has made its mission much more complex and consequently the economic, technical and social networks of government and the values distributed within the social networks have become composite. The same can be said about the academy. As long as the university employed a small elite of researchers and students, it was easy to keep its identity, values and networks. With increased resources and increased demands from the resource-providers, university's tasks have multiplied, as have its networks.

Thus, the fact that the three types of organizations discussed are based on different missions result in different social capitals. These social capitals are an outcome of both intended and unintended investment. Over time, along with the development from industrial society to knowledge society, the social capitals of organizations have become more complex. Without considering the different missions and the differences in social capital of the three types of organizations modern innovation policies prescribe that they should interact and create innovations. The problem is described in Figure 3. The traditional activities of the types of organizations are marked with an $\mathrm{O}$. The consequence of innovation policies is that actors of the three organizational types partly should expand their activities to the fields traditionally upheld by the other types of actors. A successful fulfilment of these expectations demands new strategies for combining the organization's core activity, O, with the new activities (o) that it with few exceptions not has been involved with previously. From a social capital point of view this means that, in order to support this cross-sectorial interaction, new links across sectors need to be formed and partly new norms and values need to be established. 


\begin{tabular}{|l|l|l|l|}
\hline & \multicolumn{3}{l|}{ Type of organization } \\
\hline Activity & University & Government & Firm \\
\hline Education \& Research & $\mathrm{O}$ & $(\mathrm{o})$ & $(\mathrm{o})$ \\
\hline Public infrastructure and service & $(\mathrm{o})$ & $\mathrm{O}$ & $(\mathrm{o})$ \\
\hline Product development and production for profit & (o) & (o) & $\mathrm{O}$ \\
\hline
\end{tabular}

Figure 3. The traditional activity of the three types of organization, $\mathrm{O}$, and the activities expected by modern innovation policies (o).

\section{The role of bonding, bridging and linking social capital}

It has been argued that "bridging social capital has a larger (positive) impact on economic growth than bonding social capital" (Beugelsdijk and Smulders, 2009). However, as pointed out by Westlund and Bolton (2003) such a claim is very dependent on the context and the measures being used for bonding and bridging social capital, respectively. It can easily be shown that what is bridging social capital at one (spatial or organizational) level is bonding social capital at another level. Take e.g. the social links between the researchers of two separate departments of a university; from the departments' perspective, these links are bridging, but from the university's perspective, these links are bonding links within the university. The links between inhabitants of two different neighbourhoods in a city are bridging from the neighbourhoods' perspective but bonding from the city's perspective, etc. Regarding the measures of bonding and bridging social capital, it is of course possible to find measures of both bonding and bridging that are more or less connected to economic growth and thus gives stronger or weaker - or even negative - impacts. In our view, it is not a question of whether bonding or bridging social capital has a stronger impact on economic growth, but to realize that there for each (organizational or spatial) unit exist an optimal combination of bonding and bridging social capital when it comes to its impact on economic growth.

When it comes to linking social capital, the vertical relationships between actors with different possession of power, it is neither there possible to just state that 'the more social capital, the better for economic growth'. It is the qualities of the linking social capital that matters here. The linking social capital that brings social cohesion, and stability should in 'normal' market democracies be considered as positive for economic growth, since cohesion and stability decrease uncertainty, which in its turn facilitates investment decisions. In addition, the function of linking social capital that facilitates access to resources, ideas, and information between grassroots and decision-makers should play a positive role for growth.

There are, however, cases in which linking social capital might act as an obstacle for economic growth. From a Schumpeterian perspective, the path-breaking innovations that lay the foundation to long periods of economic growth also brings 'creative destruction' to obsolete combinations of production factors. However, it is reasonable to assume that also obsolete formal and informal institutions (i.e. in the latter case social capitals) are being threatened by the potential path-breaking innovations. ${ }^{8}$ If the new, revolutionary combinations of production 
factors threaten the dominating actors of the existing linking social capital in an economy, these actors have strong incentives to prevent the breakthrough of the new technology.

Also from a non-Schumpeterian perspective it should be recognized that certain general hierarchical relations between actors (i.e. linking social capitals) might contribute to or coexist with conformity, lack of tolerance of non-established behaviour, even censorship, and 'too much' stability. In these cases, the linking social capital functions as a protection of obsolete vested interests that stand in the way for the creative thinking and activity, entrepreneurship and innovation that new actors can contribute to and that result in economic growth (cf. Section 5 of this paper).

\section{Creativity and creative processes ${ }^{9}$}

\subsection{What is creativity?}

Törnqvist (2011) maintains that the word creativity derives from the Latin verb creare, but its use in modern vocabulary is quite recent. Citing the Oxford English Dictionary, he states that it first appeared in a book about dramatic literature (Shakespeare) in 1875 and that it entered in the Francophone countries much later, i.e. after world war two. In recent decades, however, the literature on creativity has literally exploded. A search on Google Scholar on the word 'creativity', for instance, yields more than 1.2 million hits, of which more than half pertains to articles and work dated 2000 and later. ${ }^{10}$

Creativity is difficult to define, measure and narrow down. Without exaggerating, one can say that there are as many definitions and conceptualisations as there are papers and books on the concept. Some examples of conceptualisations are as follows (Rhodes 1961, Im 1999):

- Creativity refers to the personality traits of individuals that facilitate the generation of new ideas

- $\quad$ Creativity is the process of generating new ideas

- Creativity is the outcomes of creative processes

- $\quad$ Creativity regards milieus conducive to new ideas and behaviour

Historically, studies of creativity has focused on highly successful individuals in the arts as well as great inventors, such as Thomas Edison, Alexander Graham Bell too name a few. Therefore, creativity was often associated with the arts and exceptionally imaginative and gifted individuals developing new technology with an (possible) industrial use. Current work has a broader perspective, and focus on creativity as something that is economically valuable, team-based, observable and learnable (McWilliam 2007).

Boden $(2004$, p. 1) defines creativity as 'the ability to come up with ideas that are new, surprising, and valuable'. This definition affords a broad perspective and emphasizes that creativity spans much more than the creation of cultural artefacts, expressions and radically new technology. Creativity is instead an ability of individuals, or groups of individuals, to generate 
ideas, which are perceived by relevant specialists to be new and useful for other creators, consumers and/or producers.

\subsection{Creative processes and the sources of creativity}

Closely connected to any discussion of creativity is the notion of creative processes at the micro-level, i.e. how creativity comes about at the level of individuals or at the level of small teams of individuals working together. ${ }^{11}$ Our understanding of creativity at the micro-level is yet rather limited. There has been numerous studies attempting to get a grip of the creative process that have employed laboratory studies as well as detailed examinations of historical accounts of major discoveries of men like Newton, Darwin and Einstein, but the underlying mechanisms of illumination remains elusive (Schilling 2005).

Some aspects of creative processes may be understood by elucidating key characteristics of the human brain. Andersson (1985a) emphasizes a number of attributes of the human brain that pertain to creativity and creative processes. These include the human brain's capacity:

- To use heuristic reasoning such as to associate ideas, to formulate problems, to be perceptive, to discover and so on.

- To remember important facts and theories

- To detect deep structures in a system of overlaid and interdependent structures

- To detect and use ambiguity and manifoldness such as the ability to deal with seriously non-linear psychological processes

- To appreciate paradoxes and surprises

- To use and react upon experienced disequilibria

- To use fundamental uncertainties and structural instabilities.

There is indeed a long tradition in creativity research to focus on individual cognitive characteristics and traits that are associated with creative outcomes (Sternberg 1985, Tardif and Sternberg 1988, Glynn 1996). The bulk of studies on creativity have put the individual at centre stage (Montuori and Purser 1996), which may be explained by the traditional focus on artistic and inventor 'geniuses' as prime examples of creativity.

Modern work on creativity yet emphasizes the role of interactions between people and combinations of knowledge, ideas and information, and more generally the social dimension of creativity. In the classic paper on Creativity and Regional Development (Andersson 1985b), Àke E Andersson argued that understanding creativity requires a discussion of four related concepts:(i) information, (ii) knowledge, (iii) competences and (iv) creativity. He provides the following definition of each (ibid, p.13):

- Information: the most elementary concept with very limited structure and can consequently be disaggregated and aggregated without losses. 
- Knowledge: structurally ordered information. One may view information as variables, whereas knowledge is a set of equations containing these variables. Concepts, ideas and patterns are subsets of knowledge.

- Competences: embodied knowledge, which means that competence is knowledge regulated by the human body in its relation to other humans, machines and the environment.

- Creativity: the concept with the highest order. Creativity presumes a capacity to order and reorder information with the aid of a knowledge system.

Based on these concepts, Andersson (1985b) concluded, "the creative process is synergetic and dynamic, implying that information, knowledge and competence are brought into an intensive interaction with each other in order to fashion new knowledge or competence".

This characterization of creative processes emphasize that they involve both mental and social dimensions. The mental dimension refers to individuals' capacity to combine information and knowledge from different sources and contexts to create something new. The social dimension is reflected in that social interactions, i.e. interaction between people, are often needed to be exposed to and to absorb new information and knowledge that can be combined with the existing information and knowledge of an individual or group of individuals.

Andersson (1985b) provides an example of how Gutenberg solved the problem of finding a simpler method to replace the laborious carving of letters in wood in the development of the printing process. Gutenberg struggled with solving this issue for a long time, but his accumulated competence in printing technology was not sufficient. Citing Koestler (1975), Andersson (1985b) describes how it was not until Gutenberg interacted with workers and technicians in the wine industry and saw the wine pressing technique that he found out how to do it. "When the possibility to print with lead was combined with the old regional wine pressing competence the printing process could be created" (ibid, p.15).

This example illuminates that creativity is much about combining existing knowledge, information and competence from different contexts, and that this leads to discovery of new ideas or concepts, or new associations between existing ideas or concepts. ${ }^{12}$ This means that there is a strong connection between creative processes and Schumpeter's (1934) notion of innovation as 'novelty by combination'.

The idea that combination of information and knowledge from different contexts is important for creativity is actually embedded in the classic writings of Adam Smith. In arguing for the role of specialization in stimulating productivity, he implicitly remarks that specialization my limit creativity (Smith, 1776/1937, 734): "[t]he man whose whole life is spent in performing a few simple operations, of which the effects are perhaps always the same. Or very nearly the same, has no occasion to exert his understanding or to exercise his invention". He further maintains that "those who are called philosophers or men of speculation, whose trade is not to do anything, but to observe everything; and who, upon that account are often able of combining together the powers of the most distant and dissimilar objects". Karlsson (2011) argues 
Smith means to say that persons whose tasks are 'not to do anything' are theorist, and that when Smith records that such a person observes everything, the meaning is that he or she must talk to many different people. The observation that the same person is good at 'combining together' additionally implies a superior ability to combine disparate and dissimilar knowledge. Almost 150 years later, Alfred Marshall (1920, p. 225) elaborated on Smith's insights by describing the process by which knowledge variety stimulated the emergence of new ideas: "[I]f one man starts a new idea, it is taken up by others and combined with suggestions of their own; and thus becomes the source of further new ideas". This again associates to Schumpeter's (1934) notion of 'novelty by combination'.

Combination and reorganization of existing ideas and knowledge are thus fundamental in creative processes, and this has been labelled 'bisociation' (Koestler, 1964). The scope for bisociation is greatest where there can be interactions between people and exchange and dissemination of information and knowledge in heterogeneous groups. The influence of various contextual factors, including the social environment on individual creativity, has been documented by, for example, Amabile (1988) and Amabile et al., (1996). Woodman et al (1993) stress that the group constitutes the social context within which creative behaviour occurs, and Hargadon and Bechky (2006) present evidence that many creative solutions are the product of collective creative processes. This reinforces the argument of a social dimension of creativity and creative processes.

Combining and re-organizing existing ideas and knowledge yet of course require that individuals and groups have absorptive capabilities, i.e. an ability to recognize, assimilate and evaluate information, ideas and concepts (cf. Cohen and Levinthal 1990). In the previous example of Gutenberg, for instance, he needed to absorb, assimilate and evaluate the wine pressing technique in relation to the context of his own problem with the printing press. Törnqvist (2011, p.11), for instance, states, “... skilled specialists are in a position to understand the significance of an everyday experience only after having devoted a great deal of thought to a problem and performed many experiments". In line with this, Koestler (1964, p. 95) rightly emphasize capacities to "perceive ... a situation or an event in two habitually incompatible associative contexts" in creative processes. Thus, the capacities to select, re-shuffle, combine, or synthesize already existing facts, ideas, faculties and skills in original ways may be understood as essential for creativity. ${ }^{13}$

\subsection{The role of the local milieu context for creativity}

A main conclusion from the previous section is that the social dimension of creativity is important. Social interactions, i.e. interaction between people, are often needed to be exposed to and to absorb new information and knowledge that can be combined with the existing information and knowledge of an individual or group of individuals. It follows that the characteristics in of the local environment people operate in may play an important role in fostering creativity. The reason is that the local environment in many cases defines the interaction arena' and this differs greatly in terms of the variety in experiences, knowledge bases, education, etc., of its inhabitants. The local environment may thus be claimed to have a strong influence on the variety of ideas and perspectives that are exposed to individuals. 
We introduce the established concept of local milieu to characterize all the resources available for every economic actor in a given locality, such as a municipality, a town, a city or even a district within a city. The milieu approach mainly tries to analyse and explain how a good regional endowment in terms of universities, research laboratories, public support organizations and firms, if combined with certain efficient means of inter-organizational interaction and coordination, can lead to highly positive regional outcomes not least in terms of creativity (Fromhold-Eisebith, 2004). It is a generally accepted fact that some local milieus are more creative than other local milieus independent of which field of creativity we are taking about (Storper, 1997; Florida, 2002). Creativity is concerned with thought and action (at the level of both the individual and the group) directed to the generation of novel insights and perceptions that may or may not have tangible significance (Scott, 2010).

What then makes a local milieu creative? In addition, what is the role of social capital in this context? There is since several decades more or less an agreement in the literature that in particular exceptional creativity calls for opportunities to learn from diverse knowledge bases partly consisting of tacit knowledge, to bring together habitually incompatible ideas and to combine them in a way that gives deep new insights, i.e. to generate novel combinations (Koestler, 1964; Simon, 1985). Ideas are carried in the minds of people and bringing ideas together demands opportunities for people with different backgrounds to interact face-to-face and since we here are talking about incompatible ideas that should be brought together we are not talking about occasional or accidental interactions face-to-face but persistent, frequent and varied such interactions over longer periods. Interpreting and synthesizing ideas, concepts, information and knowledge involves constant questioning and re-interpretation through a process of trial, feedback and evaluation that is much facilitated by frequent face-to-face communication. Furthermore, many of the individuals involved have different backgrounds and often do not even share key concepts, which generate a need to develop a common language in order to coordinate the creative sub-processes. Such persistent and frequent communication can only occur if these persons are located in the same local milieu.

Given the emphasis on the role of interactions between people and exposure to different types of ideas, knowledge and information, it is clear that the local context in which people operate will have a strong influence on creativity and creative processes. Contexts in which there is a great pool of potential interactions with other people with a variation of ideas, knowledge, competence and creative abilities offer the best general opportunities for creativity and creative processes and for the initiation of increasing returns in creative activities. The diversity of people with varying skills, knowledge and competence is of critical importance since it is generally accepted that multidisciplinary teams, by helping individuals overcome the blinders created by their own particular expertise, most efficiently link concepts developed in one technology to problems developed in another (Desrochers, 2001)

However, the potential for such interactions is a function of a number of underlying factors, since recent research demonstrates that the most dynamic and creative local milieus are those that have both strong local interaction (collaboration and competition among local actors) and strong linkages to other local milieus of knowledge and creativity around the world (cf. Salone \& Segre, 2012): 
- The local networks of actors. These are the networks where individual, public and private actors interact with each other in different constellations. These networks are embedded in the local milieu through relationships of proximity and social capital.

- The local economic and social milieu, which is made up by immobile and semiimmobile idiosyncratic resources that have been created partly through long-term investment and migration processes. These resources are both material (infrastructures, man-made amenities, etc.) and immaterial (culture, knowledge base, institutions, social capital, etc.).

- The interactions between the local networks of actors, i.e. the local buzz (Bathelt, Malmberg \& Maskell, 2004), which determine to what extent ideas, information and knowledge is diffused between and absorbed within the different local networks.

- The interactions between the local networks of actors and other local, regional, national and global networks, i.e. global pipelines (Bathelt, Malmberg \& Maskell, 2004), which determine the flows of ideas, information, knowledge, people, firms, goods and services to and from other locations.

Against this background, it seems safe to claim that the local milieu is critical for creativity and creative processes. The most successful creative local milieus are those that combine a rich local milieu, where ideas, concepts, information and knowledge circulates with relative ease across disciplinary and organizational boundaries, with a high degree of openness and interaction with other dynamic and creative local milieus. The local milieu is the nexus of exchange where individuals with different skills, knowledge, competence and experiences belonging to different local as well as non-local networks interact in different ways to generate new ideas, new concepts, new knowledge and new inventions that might be turned into innovations.

It is important to observe that the local milieu is not an active creative agent but it provides the components and resources of the local setting for creative processes. In line with the resource-based view, we can claim that the performance of a local milieu in terms of creativity depends on its resources and capabilities (Wernerfeldt, 1984; Barney, 1991). Valuable, rare, non-imitable and non-substitutable resource configurations lay the foundation for the creative capabilities of a local milieu. However, the world is continuously changing and the local milieus face the risk that the old resource-base will become obsolete leading to a declining creative performance. Therefore, the resource configurations need to be renewed regularly. The framework of dynamic capabilities offer a foundation on which to assess the capabilities needed in the transformation process of a local milieu (Teece, Pisano \& Shuen, 1997). The dynamic capabilities of a local milieu can be defined as those processes that use resources, especially the processes that integrate, reconfigure, gain and release resources to match the changes locally and in the surrounding world. Thus, the dynamic capabilities are the organisational and strategic routines by which local milieus achieve new resources configurations for creative processes as the local and external conditions change. Unfortunately, for the local milieus, many of these routines are not controlled by the responsible policy makers but by 
firms and households. Furthermore, local milieus may be confronted with problems of adjustment due to inertia or negative lock-in effects (Grabher, 1993).

We might in line with Camagni (1991) define a creative local milieu as the set or the complex network of mainly informal social relationships in a limited geographical area, often determining a specific external 'image' and internal 'representation' and sense of belonging, which enhance the local creative capability through synergetic and collective creative processes. However, this definition is very general and based upon what we have seen in the literature, we claim that the following characteristics of local milieus tend to stimulate learning and creativity:

- Diversity in terms of ideas and specialized knowledge and competence in the local milieu stimulates creativity (Jacobs, 1969; Saxenian, 2000; Desrochers, 2001). Diversity is not the absence of specialization, but rather the presence of multiple specializations based on comparative advantages at the level of economic agents (Leppälä, \& Desrochers, 2010):

O Ordinary creativity is stimulated by diverse but semi-related ideas and specialized knowledge and competence, i.e. ideas, knowledge and competence with sufficient cognitive proximity for easy communication. “...novel combinations are promoted by a constellation of separate, relatively small, weakly connected, spatially proximate units in complementary activities" (Noteboom, 1999, 144).

- Exceptional creativity, which is rare, is stimulated by diverse but unrelated ideas and specialized knowledge and competence. "It would therefore seem plausible to believe that the local presence of unrelated activities might not only enhance the capacity of individuals to see new possibilities, but also to act upon them" (Desrochers, 2001, 387).

- Size stimulates creativity, since the larger the local economic milieu, the greater the variety of skills, knowledge, experiences and competencies and the larger the possibilities to form the right multi-disciplinary teams. There are also more opportunities and lower costs for interaction and the diffusion of ideas, information and knowledge in large local milieus.

- Density, i.e. a high accessibility between people, which generate proximity among people, stimulates creativity by making face-to-face interaction less costly and less time consuming (Gordon \& Ikeda, 2011).

- Openness and tolerance to new ideas and cultural diversity stimulate creativity (Saxenian, 2000; Florida, 2002).

- Well-developed formal and informal institutions that clarify property rights and reduce transaction costs stimulate creativity.

- A high exposure to imported ideas, knowledge and products stimulates creativity. 
- A high in-migration of people with diverse ideas, knowledge, skills and competence stimulates creativity (Saxenian, 2000).

- Market access stimulates creativity. This is a general observation but is of course most obvious in the arts sector.

Even if we at least partly understand what factors in the local economic milieu that stimulates creativity, it is by no means easy by policy measures to create creative local milieus. Certainly, policy makers can invest in infrastructures, amenities, public services, R\&D and higher education. However, at the same time we must acknowledge that much of the local development is path dependent, often initiated by some historical event, i.e., chance, and a function of migration and investment decisions by individuals and firms, i.e. selection processes. Path dependency might create difficulties for local milieus to adapt to changed external conditions due to a limited learning capability when faced with new circumstances. Thus, after a period, local milieus may become victims of their earlier success and lose their creative capacity for a variety of reasons. Policy decisions can be instrumental for where the flows will go but at the same time there are numerous examples of such policy initiatives that have totally failed and it is very difficult ex ante to know which initiatives will be successful and which will fail, since the locational pattern of creative processes is unpredictable.

\subsection{How is creativity materialized?}

Creativity can be materialized in a variety of ways. We will here focus on creativity as captured by entrepreneurship and innovation.

It is common to relate creativity to innovation. Amabile et al. (1996) states: "All innovation begins with creative ideas ... We define innovation as the successful implementation of creative ideas within an organization. In this view, creativity by individuals and teams is a starting point for innovation; the first is a necessary but not sufficient condition for the second" (ibid, 1154-1155). Creativity is thus typically used to refer to the act of producing new ideas, approaches or actions, while innovation is the process of both generating and applying such creative ideas in some specific context. Despite this difference in the definitions, innovation is usually considered an accepted proxy for creativity and creative processes. Individuals and organizations introducing innovations, as well as regions in which such processes takes place, are typically considered creative.

In the economic research literature, definitions of innovations include, “...putting new products and services on the market or new means of producing them" (Bannock, 1992), “...the economic application of a new idea" (Black, 1997), “...the implementation of changes in production (...) [or] the introduction of new types of commodities on the market" (Suranyi-Unger, 1982). These definitions stress an important feature of an innovation, namely that it has to be used on the market to be classified as an innovation. Thus, it has to be involved in a commercial transaction. ${ }^{14}$ Thereby, innovation share features with modern definitions of creativity, which emphasize usefulness, value and novelty as important characteristics of creativity.

Entrepreneurship can be described as 'an activity that involves the discovery, evaluation and exploitation of opportunities to introduce new goods and services, ways of organizing mar- 
kets, processes and raw materials' (Shane 2003, p.4). An entrepreneurial opportunity is a situation, which enables this activity (Shane and Venkataraman 2000, Casson 2003) and typically consists of a combination of ideas, knowledge and actions (cf. Saravasthy et al., 2003). Knowledge is perceived as the primary basis of new firms and it plays a fundamental role in the recognition and capitalization of entrepreneurial opportunities. Schumpeter's definition of entrepreneurship placed an emphasis on innovation by novel combinations. In his writings, innovation may refer to new products, new production methods, new markets or new forms of organization.

The idea of 'novelty by combination' links up the discussion of the role of variety of knowledge and 'social dimension' for creativity. Entrepreneurs that, for instance, combine existing knowledge and/or exploit entrepreneurial opportunities to produce novelties on the market certainly can certainly be describes as creative or at least initiating creative processes. Note also that as entrepreneurs bring in novelties to market, either in the form of new firms or existing firms, entrepreneurship also conforms to the arguments that creativity should also reflect usefulness, value and novelty.

In summary, both entrepreneurship and innovation are measurable phenomenon at the individual and collective levels that can be claimed reflect creativity and creative processes.

\section{Social capital as an explanatory factor for individual and collective creativity}

\subsection{The general importance of social capital for creativity}

In the previous section, we provided arguments for the role of the local milieu in creative processes, as they constitute 'interaction arenas'. The role of 'interaction arenas' was derived from the social dimension of creativity. We also provided a discussion of number of characteristics of local milieus that should foster creativity. We begin this section with a discussion of social capital as a milieu characteristic of importance for creativity, in general, and then go on to discuss the relationship between social capital and collective and individual creativity, respectively.

That people is located in the same local milieu is no guarantee that interactions, in particular face-to-face interaction, will occur. There is also a need for arenas and meeting places where such interactions can occur as well as networks, norms, attitudes, incentives, resources, information, knowledge, competence, etc., which create a foundation for meaningful interactions. It is with regard to these latter aspects that social capital comes into play. Spatial proximity and social capital are essential because they together stimulate a process of collective learning, which lowers transaction costs and encourages co-ordination between economic actors (Boschma and Lambooy, 1999). This is mainly achieved through, i) the mobility of human capital as the carrier of (often tacit) knowledge, ii) the transfer and feed-back of information via dense (mainly informal) networks of local actors, and iii) a common local culture of trust, i.e. social capital, based on shared practices and rules. This implies that the idea, 
information and knowledge externalities that are critical for creative processes are indeed localized geographically.

Social capital is expected to foster stronger inter-firm ties, certain interpersonal dynamics (primate of trust and reciprocity), and a common context, language and code of behaviour of individuals that is integrated the structure of the local milieu (e.g. shared terms and experiences) (Lesser, 2000). It follows that social capital can be imperative in stimulating creativity as common norms, shared conventions, rules, values, and attitudes are vehicles for learning, the development of communications and common knowledge interpretations. However, as emphasized by the discussion in the previous section, the local accumulation of social capital is not a sufficient condition for the emergence of comparative creative advantages. The local accumulation of a varied human capital, (intangible, un-coded) knowledge, information linkages, network externalities (technological spillovers) and supportive institutions of the right and complementary kind must support it.

A further argument for social capital is provided by the big literature on the role of tacit knowledge in innovation processes, which we recognize should reflect creative processes. In contrast to explicit knowledge, i.e. easily codified and "disembodied" knowledge, tacit knowledge is knowledge that cannot be transformed to explicit. Skills and routines are examples of tacit knowledge, (Lorenzen, 1998). Tacit knowledge tends to coexist in very different activities such as scientific research and traditional manufacturing production, (Grimaldi \& Torrisi, 2001). This can be explained by the fact that knowledge is inclined to always be partially tacit in the minds of the creators, (Saviotti, 1998). Hence, the importance of formal education does not oppose a significant role of tacit knowledge. Lawson \& Lorenz (1999) affirm that tacit knowledge has a role to play for innovation processes in high technology sectors, which generally use formal knowledge and R\&D extensively.

The reasons given for the role tacit knowledge plays are many. Firstly, it is suggested that experiences, skills and know-how, which by definition represent tacit knowledge, are without doubt important inputs in an innovation process. Secondly, tacit knowledge seems to be important to keep actors up to date and to share knowledge and in development processes. The rationale for this is that new knowledge is not devised codified (Fischer and Varga 2001, Saviotti 1998). The degree of knowledge explicitness is low in the development stage of new knowledge, such as the development process of Gutenberg's printing technology. Lawson \& Lorenz (1999) discuss the relative importance of tacit knowledge in different phases of an innovation process. They differentiate between four stages. The first entails sharing of tacit knowledge, the stage in which many of the new ideas are generated. In the second, the ideas become articulated and can be formulated more precisely, i.e. the ideas are made explicit. After the second stage, the explicit ideas are combined with other known technologies and methods and it is in this third stage that prototypes are made. The third stage stands for the process in which explicit knowledge is combined. In the fourth, a new product is produced. New routines and skills, i.e. new tacit knowledge, are developed upon which new knowledge may be created. Thus, the knowledge used in the early phases of an innovation processes is mostly tacit and is important in order to keep up with other firms' developments, such as new ideas on technical solutions and so forth. 
The role of social capital in transmission and exchange of tacit knowledge is made clear by that it necessitates that both the receiver and the transmitter are familiar with the 'code' of the tacit knowledge. Reciprocal understanding of codes demand prolonged interaction between the transmitter and the receiver. Lawson \& Lorenz (1999) maintain that such elements may be developed through strong local institutions, intensive collaboration between firms or labour mobility, i.e. social capital. The literature on the role of common conventions and rules shared by actors, i.e. informal institutions, for the smoothness of knowledge transfers and spillovers is huge, (see e.g. Storper 1995, Maillat 1995, Maillat and Kebir 2001). In principle, this strand of literature tries to give an in-depth explanation of the emergence and importance of local cultural institutions, which according to Lawson \& Lorenz (1999) may generate shared tacit knowledge. It is maintained that not only geographical proximity but also relational proximity play a prominent role. The latter encompasses relations developed by integration of firms and socio-cultural homogeneity (Capello, 2001), and can be related to Storper's (1995) untraded interdependencies and Maillat's (1995) atmospheric externalities. Thus, common rules and conventions bring about mutual trust, which diminishes uncertainties, stimulates, and facilitates interaction. As Harrison (1996, p.235) writes: '[B]y increasing the likelihood of familiarity, proximity reduces the incidence of opportunistic behaviour by suppliers, customers and even competitors, thus facilitating learning'.

Finally, it should be underscored that it is not only the 'tacit' or explicit similarity between actors that create the base for a favourable social capital. Social capital is also based on actors' complementarity. Expressed in network terms, this means, "without heterogeneous characteristics (...) the nodes would be identical, would lack relative deficiencies and surpluses of different factors, and would therefore have no cause either to give or to receive flows in a network. Exchange in a network consists of flows of factors of which certain nodes have a relative surplus and others have a relative shortage. As long as the aggregate returns exceed the costs of the flows, exchanges within the network will continue. A plausible hypothesis might be that every network may require a specific combination of homogeneous and heterogeneous characteristics in its nodes for it to arise and survive. In extreme cases, i.e. with total homogeneity or total heterogeneity of the nodes, no network can exist" (Westlund 1999, p 104).

\subsection{Social capital and collective and individual creativity 15}

In what way do different types of social capital contribute to individual and collective creativity, respectively? Below we discuss these issues using entrepreneurship and innovation as processes reflecting creativity.

Expressed in simple terms, the social capital that promotes entrepreneurship and innovation consists of networks and links between actors that are entrepreneurial and innovative. ${ }^{16}$ This means that it is the actors' values - or expressed in other terms, the cognitive social capital of the actors - that are the decisive factor for whether social capital contributes to creativity in the forms of entrepreneurship and innovation, or not. In this perspective, the actors' values mainly decide which other actors to link to and with which networks to connect. If creative actors form networks of likeminded, they simultaneously form a social capital that stimulates further creativity within the networks. 
From the sectorial perspective it can be argued that it is the social capital that promotes creativity in the business sector that has the strongest influence on economic growth (Westlund and Adam 2010), while creative-supporting social capital in the public sector, universities ${ }^{17}$ and the third or voluntary sector is of less importance for economic performance. However, such a conclusion is not in full conformity with the ideas of cross-sectorial growth policies, as e.g. those of innovation systems and triple-helix. First, creativity that leads to innovations in the non-business sectors might have indirect effects on the economy: higher efficiency in the public sector can result in lowered taxes, which stimulate the economy; new organizations and methods in the third sector can reduce social problems, save public expenses and increase the supply of labour, etc. Second, as discussed in the former subsection, the theories of innovation systems postulate that knowledge spillovers and other creative exchange of resources across sectorial borders contribute to innovation and economic growth. These cross-sectorial spillovers and more organized exchange of resources are facilitated if the actors of each sector respectively belong to cross-sectorial social networks and if they understand and accept values and norms that occur in other sectors than the own one.

What we have said so far in this section is related to creativity as a collective phenomenon, i.e. creativity because of collective values, norms and attitudes, being exchanged in social networks. As social capital itself is a collective phenomenon, it is not hard to find arguments for that it is having an impact on collective creativity. A more thorny issue is how social capital is related to individual creativity.

Yet, a good example of how social capital may influence individual creativity is given the literature on the role of entrepreneurship culture, understood as a subset of social capital, may foster individuals to start new firms, i.e. become entrepreneurs. As argued previously, this is a process with clear associations to creativity.

In her well-known book, comparing California's Silicon Valley and the Route 128 corridor outside of Boston, Anna Lee Saxenian analyses why the two regions embarked on such different development paths. While both regions had a historically strong concentration of knowledge- and technology-intensive sectors and bright prospects for a resilient economic development, the regions developed along different trajectories after the crisis period in the mid-1980s. Silicon Valley continued to flourish whereas Route 128 declined. Saxenian maintains that one important explanation for the divergent performance of the regions is rooted in differences in local social capital pertaining to entrepreneurship; henceforth we may call this regional entrepreneurship culture. The following statement from an entrepreneur with experience from both regions may serve as a case in point (Saxenian 1994, p 63):

"In Boston, if I said I was starting a company, people would look at me and say: 'Are you sure you want to take the risk? You are so well established. Why would you give up a good job as vice president at a big company?' In California, I became a folk hero when I decided to start a company. It wasn't just my colleagues. My insurance man, my water deliverer - everyone was excited. It's a different culture out here." 
A Swedish example of such kind of locally embedded entrepreneurship culture is the socalled 'Gnosjö-spirit' (cf. Wigren 2003). This spirit is widely recognized in Sweden and is even listed in the Swedish National Encyclopaedia. It is described as follows therein (author's translation):

"The Gnosjö spirit refers to the enterprising culture that prevails in the municipality of Gnosjö and its neighbors in the county of Småland. In this region, self-employment is a way of life that dominates the local community, which for instance implies that the local authorities, banks, and trade unions conform their way of working to the way the enterprises work."

This reflects the quite common argument that there are locally embedded values and attitudes towards entrepreneurship, exerting a strong influence on the rate and level of entrepreneurial activity in regions (Westlund and Bolton 2003). The concept of regional entrepreneurship culture aims to capture such phenomena, and refers in a general sense to the level of social acceptance and encouragement of entrepreneurs and their activities in a region (Fritsch and Wyrwich 2012).

There is strong evidence in the literature that such kind of entrepreneurship culture, as a subset of social capital, are important in promoting individuals to start new firms. A main piece of evidence is that rates of new firm formation across regions are highly persistent (Andersson and Koster 2011). Why is persistence of regional variations in new firm formation rates often interpreted as evidence of entrepreneurship culture? Culture is by definition a phenomenon that changes in slow processes. Williamson (2000) outlines different types of institutions and their time scale of change. Williamson argues that social 'embeddedness' is the highest level of institutions and that "...this is where the norms, customs, mores, traditions, etc., are located" (p. 596). This kind of informal institutions change very slowly over centuries or millennia. They also impose constraints on other (formal) institutions as well as the general workings of the economy. Resource allocation and employment in the economy changes continuously, and on a much faster time scale than institutions. A regional entrepreneurship culture may be defined as spatially localized informal institutions (i.e. social capital) that have to do with the general social acceptance and encouragement of entrepreneurs and their activities in a region. In view of this, the main argument is that informal institutions such as regional entrepreneurship cultures are a historically rooted component part of regional social capital and evolve in slow processes over time, so should the phenomena dependent on it.

What kind of social capital is relevant in the context of entrepreneurship cultures that stimulate individual creativity in the form of new firm formation? The literature emphasize social capital that stimulate learning from role models and learning from the environment. The literature typically emphasizes social capital that stimulate 'entrepreneurial learning', and the role of imitation and entrepreneurial role models in such processes. Recognizing and acting upon business opportunities are inherently processes at the individual level, but the context in which these processes manifest themselves is important in shaping individual responses (Verheul et al. 2001). Guiso and Schivardi (2005) argue that entrepreneurial talent is not innate and maintain that when more entrepreneurs are active in a region, people will have 
greater opportunities to acquire entrepreneurial skills. According to their framework, an individual's accumulation of entrepreneurial skills is partly a function of the regional intensity of entrepreneurs.

Entrepreneurial role models have indeed been shown to have a positive impact on the propensity of people to start new firms (Aldrich 1999, Blanchflower and Oswald 1998, Arenius and Minniti 2005). Knowing an entrepreneur and having an entrepreneur in the family are good estimators of entrepreneurship. Entrepreneur role models not only assist in developing entrepreneurial skills, they are also a sign of the social acceptability of entrepreneurship. In addition, existing entrepreneurs may serve as bellwethers of certain business opportunities that imitative entrepreneurs may follow (Baumol 1993). As such, this means that role models also influence the recognition of opportunities. At the regional level, a wide availability of role models may thus generate 'demonstration effects', such that potential entrepreneurs are stimulated to develop an idea in the form of a new firm. ${ }^{18}$

In summary, accepting new firm formation by individuals as reflecting individual-level creativity, there are clear examples from the literature on how social capital that stimulates learning and role model effects.

\section{Creativity - an element of social capital?}

In this paper, we have been analysing creativity and social capital, and their role for economic performance. We have argued that social capital can contribute to, or counteract, creativity and that creativity changes the social capital of existing domains and even contributes to the emergence of new domains with new social capitals. However, is it also so that creativity is a component part of certain social capital? Our answer is yes - with emphasis on certain.

If creativity can form a component part of social capital, this cannot be a part of the social capital that Putnam has made well known, i.e. the social capital of stable, homogeneous networks with stable norms and values that brings stability and make people feel safe and trust each other. Putnam (1993) showed that variations in this type of social capital historically were related to a positive economic development among the regions of Italy. Other studies have also found support of this relationship. However, as shown by the meta-study of Westlund and Adam (2010) the correlations between the Putnamian, stable type of social capital and countries and regions' economic performance are far from unanimous.

Also Putnam's (2000) own studies of the weakened social capital in the US cast doubt over the general positive relationship between stable social capital and economic growth. In spite of several decades of weakened social capital (of the Putnam type), the U.S. showed a very strong economic growth in the 1990s. It is a fact that Putnam's results even can be interpreted, as social capital is negative for economic growth: the American regions that scored the highest social capital rates were homogeneous, stagnating, depopulation regions with limited immigration the last generations. Consequently, expanding metropolises like Los Angeles showed a very low social capital in his measures. 
Our interpretation of this problem is that Putnam's homogeneous social capital in general stood in a positive, mutual, self-reinforcing relationship with economic growth during the late industrial period, which in most developed countries lasted up to the 1970s. During this period, economic growth was built on mass production based on improvement of old innovations through increased capital intensity of production, without any need for new, pathbreaking innovations. The decline of the industrial society and emergence of the knowledge economy has changed these conditions completely. Computerization and other applications of digital technology together with other emerging technologies have brought creativity, expressed in the form of entrepreneurship and innovations back as an essential engine of economic growth (Westlund 2006).

Thus, the social capital that promotes economic growth in the knowledge economy is of a different type than the social capital that Putnam 'discovered'. In the knowledge economy, innovation has become the key ingredient for success in the increasingly competitive economy - and innovation is the result of creativity. The social capital that promotes growth in the knowledge economy is consequently not the social capital of stable, homogeneous networks and norms and values. Instead, it is a social capital of flexible, much more heterogeneous networks and in which creativity, flexibility, diversity and tolerance are important norms and values. This line of ideas corresponds to those of Florida (2002).

Putnam's social capital has been criticized by among others Florida (2002) for being based on obsolete values that advocates a stagnated society with too hard social control. On the other hand, Florida's uncritical views of flexibility have also met criticism. For example, Baris (2003, p. 44) points out that Florida glorifies the contracted-out economy and its labour-market flexibility, without recognizing the other side of the coin: the temperatures and day-labourers that are forced to be flexible. Without taking a position in these discussions about what is desirable, we conclude that the social capital that supports economic growth in the knowledge economy of today is a social capital in which creativity is an essential component part.

Creativity's position as norm, value or attitude of the knowledge economy's social capital has also spatial aspects. While the last decade of the manufacturing-industrialized economy was characterized by counter-urbanization, i.e. shrinking population of metropolitan regions and population increase of smaller centres and rural areas, the knowledge economy has been characterized by an urban revival. The great metropolitan regions of the world are also the main hubs of the knowledge economy (Kourtit and Nijkamp 2012). The combination of big, local markets, concentration of human capital and creative people, and a social capital of diversity and flexibility, seems to make the metropolitan regions to the ideal centres of the knowledge economy. The role of centres at lower levels in the urban hierarchies and of rural areas is mainly determined by how these places and areas are able to connect to the metropolitan hubs (Westlund and Kobayashi 2013).

Another spatial aspect that must not be forgotten is the role of the Internet as a space for virtual social capital. Traditional research, both in social capital and in spatial sciences has very much of a traditional view of space in which (time) distances and transporta- 
tion/communication, costs are crucial factors for (social) network building. Correspondingly, face-to-face contacts are considered decisive for social capital creation as well as for creativity. However, it is hard to deny that the Internet and all its social applications have created a new, virtual space for social capital in which physical distance does not matter. There is a growing body of research on how this new, virtual social capital relate to the 'old' space bound social capital (see e.g. Ellison et al. 2007). However, the role of this new form of social capital for creativity is still an almost unexplored field of research.

\section{Conclusions}

In this paper, we have summarized integrated and synthesized literature on social capital, creativity and their impacts on economic performance. We have shown that creativity has obvious connections to social capital as creativity has a social context; it is dependent on exchange of knowledge, ideas and skills between actors, and these processes are affected by the actors' social capital. Social capital in this way exerts an influence on creativity - but not necessarily a positive influence. Depending on the actors of the networks, the types of networks and the values and norms being distributed and reproduced in them, certain social capital can promote creativity while certain social capital might inhibit it.

Creativity, on the other hand, does also influence the social capital of the actors being involved in or affected by the creative processes. In principle, creativity brings change and for social capital, this means changes in social networks and their actor composition, and changes in the norms, values and attitudes that are being distributed in the networks. Lack of creativity contributes to a stagnated social capital.

We have stressed the close relations between creativity, entrepreneurship and innovation. Creativity is a necessary property of the entrepreneur and innovation is the result of entrepreneurship. Just like its possible influence on creativity, social capital can either support or prevent entrepreneurship and innovation. It depends on which networks and which norms that dominates the social environments in which the entrepreneurial and innovative activities take place.

Entrepreneurship and creativity are high up on the policy agendas worldwide, whereas creativity and social capital are given considerably less policy attention. The latter may have many reasons but one is probably the problem in materializing the theoretical concepts in policy action that give results with a direct measurable impact on economic performance. Another reason might be that research on creativity and social capital hitherto have had very little focus on growth policy issues, which means that research so far only can come up with logic arguments but has no policy to suggest. This means a great challenge for research in the fields of entrepreneurship, innovation, creativity and social capital!

Thus, our main conclusion is that there is a great potential in integrating research on social capital and creativity with the research on innovation and entrepreneurship. This potential is not only scientific but indeed also policy relevant! 


\section{References}

Anderson, Alistair R. \& Jack, Sarah L. (2002): The articulation of social capital in entrepreneurial networks: A glue or a lubricant? Entrepreneurship \& Regional Development: An International Journal, 14(3), 193-210

Anderson, Joseph V. (1992) Weirder than fiction: the reality and myths of creativity, Academy of Management Executive, 6:4, 41.

Barney, J.B. (1991), Firm Resources and Sustained Competitive Advantage, Journal of Management $17,99-120$

Baris M (2003) Review of Richard Florida: The rise of the creative class: and how it's transforming work, leisure, community, and everyday life. The Next American City, Vol. 1, pp. 42-45.

Bathelt, H., A. Malmberg \& P. Maskell (2004), Clusters and Knowledge: Local Buzz, Global Pipelines and the Process of Knowledge Creation, Progress in Human Geography 28, $31-56$

Beugelsdijk, S and Smulders, S. (2009). Bonding and bridging social capital and economic growth. Discussion paper No. 2009-27, Tilburg University.

Boschma, R.A. \& J.G. Lambooy (1999), Evolutionary Economics and Economic Geography, Journal of Evolutionary Economics 9, 411-429

Bourdieu P (1980) Le capital social. Notes provisaires. Actes de la Recherche en Sciences Sociales 3: 2-3

Buchanan J (1965) An Economic Theory of Clubs. Economica XXXIV: 1-14

Camagni, R. (1991), Local "Milieu", Uncertainty and Innovation Networks: Towards a New Dynamic Theory of Economic Space, in Camagni, R. (Ed.), Innovation Networks: Spatial Perspectives, Belhaven Press, London, ?-?

Coase R (1937) The nature of the firm. Economica, New Series 4: 386-405

Coleman JS (1988) Social Capital in the Creation of Human Capital. American Journal of Sociology (Supplement) 94: 95-120

Coleman JS (1990) Foundations of Social Theory. Harvard University Press, Cambridge, MA

Cooke, P. \& L. Leydensdorff (2006), Regional Development in the Knowledge-Based Economy: The Construction of Advantage, Journal of Technology Transfer 31, 5-15

Csikszentmihalyi, Mihaly (1996) Creativity: Flow and the Psychology of Discovery and Invention. New York: Harper Perennial

Desrochers, P. (2001), Local Diversity, Human Creativity, and Technological Innovation, Growth and Change 32, 369-394

Ellison NB, Steinfield C, Lampe C (2007) The Benefits of Facebook “Friends:' Social Capital and College Students' Use of Online Social Network Sites, Journal of ComputerMediated Communication 12, 1143-1168

Florida, R. (2002) The Rise of the Creative Class: And how it's transforming work, leisure, community and everyday life, New York: Basic Books.

Fromhold-Eisebith, M. (2004), Innovative Milieu and Social Capital - Complementary or Redundant Concepts of Collaboration-Based Regional Development, European Planning Studies 12, 747-765

Glaeser, Edward L., David Laibson, and Bruce Sacerdote (2002) The Economic Approach to Social Capital, The Economic Journal, 112 (483) F437-F458 
Gordon, P. \& S. Ikeda (2011), Does Density Matter?, in Andersson, D.E., Å.E. Andersson, \& C. Mellander (Eds.), Handbook of Creative Cities, Edward Elgar, Cheltenham, 435-455

Grabher, G. (1993), The Weakness of Strong Ties; The Lock-In of Regional Development in the Ruhr Area, in Grabher, G,. (Ed.), The Embedded Firm. On the Socioeconomics of Industrial Networks, Routledge, London, 255-277

http://celestra.ca/top-10-creativity-definitions/ (accessed 2012-12-27)

Jacobs, J. (1969), The Economy of Cities, Random House, New York

Johansson B, Westin L (1994) Affinities and Frictions of Trade Networks. Annals of Regional Science 28: 243-261

Karlsson, C. (2011), Clusters, Networks and Creativity, in Andersson, D.E., Å.E. Andersson, \& C. Mellander (Eds.), Handbook of Creative Cities, Edward Elgar, Cheltenham, 85114

Koestler, A. (1964), The Art of Creation, Macmillan, New York, NY

Kourtit K, Nijkamp P (2012) In Praise of Megacities in a Global World. Paper presented at the 51st Annual Meeting of the Western Regional Science Association, Poipu, Kauai, Hawaii, February 8-11, 2012.

Lesser, E.L. (2000), Leverating Social Capital in Organizations, in Lesser, E.L. (Ed.), Knowledge and Social Capital: Foundations and Applications, Butterworth Heinemann, Boston, MA, 3-16

Läppälä, S. \& P. Desrochers (2010), The Division of Labour Need Not Imply Regional Specialization, Journal of Economic Behaviour \& Organization 74, 137-147

Nahapiet, J. and S. Ghoshal (1998) Social Capital, Intellectual Capital, and the Organizational Advantage. The Academy of Management Review, 23(2), 242-266.

North D (1990) Institutions, Institutional Change and Economic Performance. Cambridge University Press, Cambridge, MA

Noteboom, B. (1999), Innovation, Learning and Industrial Organization, Cambridge Journal of Economics 23, 127-150

Polanyi K (1944) The Great Transformation. The Beacon Press, Boston

Portes A, Landolt P (1996) The Downside of Social Capital. The American Prospect 26: 1821

Putnam, Robert D (1993) Making Democracy Work. Civic Traditions in Modern Italy, Princeton University Press, Princeton.

Putnam RD (1995) Bowling Alone: America's Declining Social Capital. Journal of Democracy 6: $65-78$

Putnam RD (2000) Bowling Alone. The Collapse and Revival of American Community. Simon \& Schuster, New York

Rutten, Roel, Westlund, Hans and Boekema, Frans (2010) 'The Spatial Dimension of Social Capital', European Planning Studies, 18: 6, 863 - 871

Salone, C. \& G. Segre (2012), Culture and Creativity in the Territorial Local Systems. Tales in Search for a Theoretical Scheme, Working Paper No. 1/2012, Department of Economics, University of Turin

Saxenian, A. (2000), Networks of Immigrant Entrepreneurs, in Lee, C.-M., et al. (Eds.) The Silicon Valley Edge: A Habitat for Innovation and Entrepreneurship, Stanford University Press, Stanford, CA, ?-? 
Schumpeter Joseph A (1934) The Theory of Economic Development, Cambridge, MA: Harvard University Press.

Scott, A.J. (2010), Cultural Economy and the Creative Field of the City, Geografiska Annaler: Series B. Human Geography 92, 115-130

Simon, H.A. (1985), What Do We Know about the Creative Process?, in Kuhn, R.L. (Ed.), Frontiers in Creative and Innovative Management, Ballinger, Cambridge, MA, pp. 320

Storper, M. (1997), The Regional World: Territorial Development in a Global Economy, The Guilford Press, New York, NY

Teece, D.J., G. Pisano \& A Shuen (1997), Dynamic Capabilities and Strategic Management, Strategic Management Journal 18, 509-533

Uphoff, N. (2000) Understanding Social Capital: Learning from the Analysis and Experience of Participation, In Partha Dasgupta and Ismail Serageldin (eds.), Social Capital: A Multifaceted Perspective. Washington, D.C.: The World Bank.

Wernerfeldt, B. (1984), A Resource-Based View of the Firm, Strategic Management Journal $5,171-180$

Westlund H (1999) An interaction-cost perspective on networks and territory. Annals of Regional Science 33:93-121

Westlund H (2006) Social Capital in the Knowledge Economy: Theory and Empirics. Springer, Berlin, Heidelberg, New York

Westlund H (2009) The Social Capital of Regional Dynamics: A Policy Perspective. In Karlsson, C., Andersson, Å.E., Chechire, P.C. and Stough, R.R. (Eds.) New Directions in Regional Economic Development. Berlin, Heidelberg, New York: Springer, pp. 121142.

Westlund H (2011) Multidimensional Entrepreneurship: Theoretical Considerations and Swedish Empirics. Regional Science Policy and Practice, Vol. 3, No. 3, pp. 199-218

Westlund H, Bolton RE (2003) Local Social Capital and Entrepreneurship, Small Business Economics, 21, 77-113

Westlund H, Nilsson E (2005) Measuring enterprises' investments in social capital: A pilot study, Regional Studies, 39(8):1079-1094

Westlund H and Adam F (2010) Social Capital and Economic Performance: A Meta-analysis of 65 Studies. European Planning Studies Vol. 18, No 6, pp. 893-919

Westlund H and Calidoni F (2010) The Creative Class, Social Capital and Regional Development in Japan. Review of Urban and Regional Development Studies, Vol. 22, No 2/3, 2010, pp. 89-108.

Westlund H and Kobayashi K (2013) Social Capital and Sustainable Urban-Rural Relationships in the Global Knowledge Society, in Westlund H and Kobayashi K (Eds.) Social Capital and Rural Development in the Knowledge Society. Cheltenham: Edward Elgar, pp. 1-17.

Westlund H and Li Y (2013) Analysis of local social capital, in Andersson M and Karlsson C (Eds.) Handbook of Research Methods and Applications in Economic Geography (forthcoming).

Williamson OE (1983) The Economic Institutions of Capitalism. New York, London: The Free Press, Collier McMillan Publishers 


\section{Woolcock, M. (2000a) Why should we care about social capital? Canberra Bulletin of Public Administration, 98, December, pp. 17-19}

${ }^{1}$ The two definitions below are taken from http://celestra.ca/top-10-creativity-definitions/
${ }^{2}$ Cf. Westlund (2006, p. 45): "It can be assumed that the motives for a link-investment are completely based on economic considerations, but the outcome of this "long-term" investment is dependent among other things on the social relations between the actors who establish, use and maintain the link. With negative attitudes to the link among these actors, incentives to use the link would be lower, and the link would yield lower returns than in the case of neutral or positive attitudes. Thus, it is in the interest of all the actors who invest in the link or network to establish a positive social capital among its users."

${ }^{3}$ While a majority of researchers dealing with social capital has used the term civil society, it should be noted that Putnam referred to the civic society. In practice, the difference is of course neglectable.

${ }^{4}$ For overviews, see Westlund and Adam (2010) and Westlund and Li (2013).

5 Another way of describing the bonding and bridging functions of social capital is its features as a "glue" and a "lubricant", respectively (see e.g. Anderson and Jack 2002, Rutten et al. 2010).

${ }^{6}$ One exception is Westlund and Calidoni (2010).

${ }^{7}$ This subsection is based on Westlund (2006 and 2009).

${ }^{8}$ For a general discussion on the importance of institutions for economic growth, see e.g. North (1990) and Williamson (1983). Regarding the relation between social capital and institutions, we regard social capital as being non-formalized rules, norms and values, while we reserve the term institutions for the formalized rules (see Westlund 2006, p 9).

${ }^{9}$ Part of this section draws on Karlsson (2011).

${ }^{10}$ The search was made in January 2013.

${ }^{11}$ A classic portrayal of the creative process is Wallas (1926), which suggested a model with six steps: (i) preparation, that is acquisition of the skills, knowledge and information that allow a person to create, (ii) incubation, (iii) intimation, (iv) illumination or insight - the 'Eureka moment' of Archimedes, (v) verification, and (vi) communication.

${ }^{12}$ New knowledge combinations are, according to Desrochers $(2000 ; 2001)$ accomplished by (i) multidisciplinary teams working within a firm, (ii) employees adding to, or switching, their product line, (iii) individuals moving from one type of production to another, (iv) individuals observing a product/process in another setting and incorporating it into their main activity, or (v) individuals possessing different skills and working for different firms, collaborating with each other.

${ }^{13}$ Perkins (1981) further insists that skills like pattern recognition, creation of analogies and mental models, the ability to cross domains, exploration of alternatives, knowledge of schema for problem-solving, fluency of thought and so on, are all indicators of creativity as a set of learning dispositions or cognitive habits. Many creativity researchers, such as Simonton (2000), Robinson (2000) and Sternberg (2007), maintain that there are three essential components in creativity: domain-relevant skills, creative processes, and intrinsic task motivation. It is also more often than not claimed that creativity is both a way of thinking 'associated with intuition, inspiration, imagination, ingenuity and insight' and 'novel and appropriate response to an open-ended task' (Byron 2007).

${ }^{14}$ However, Freeman (1998) points out the twofold meaning of an innovation: “...the word is used both to indicate the date of the first introduction of a new product or process and to describe the whole process of taking an invention or set of inventions to the point of commercial introduction".

${ }^{15}$ Part of this section draws on Andersson (2012).

${ }^{16}$ Here we only consider entrepreneurship and innovation that is positive for society, i.e. we leave entrepreneurship and innovation in criminal and destructive activities aside.

${ }^{17}$ It can of course be discussed whether the university is a sector of its own, like the business, the public and the third sector.

${ }^{18}$ Johannisson $(1983,1984)$ discusses and illustrates such an effect in the Gnosjö region of Sweden. 